\title{
Evaluation of Human Respiratory Syncytial Virus and Human Parainfluenza Virus Type 3 among Hospitalized Children in Northwest of Iran
}

\author{
Zahra Ramezannia, ${ }^{1}$ Javid Sadeghi ${ }^{1},{ }^{1}$ Shahram Abdoli Oskouie, ${ }^{2}$ \\ Mohammad Ahangarzadeh Rezaee, ${ }^{1}$ Hossein Bannazadeh Baghi $\mathbb{D}^{1,3}$ Arezou Azadi, \\ and Mahin Ahangar Oskouee $\mathbb{B D}^{1,3}$ \\ ${ }^{1}$ Department of Microbiology \& Virology, Faculty of Medicine, Tabriz University of Medical Sciences, Tabriz, Iran
${ }^{2}$ Pediatric Health Research Center, Tabriz University of Medical Sciences, Tabriz, Iran
${ }^{3}$ Infectious and Tropical Diseases Research Center, Immunology Research Center, Tabriz University of Medical Sciences,
Tabriz, Iran
}

Correspondence should be addressed to Mahin Ahangar Oskouee; ahangar1342@gmail.com

Received 16 May 2021; Revised 14 August 2021; Accepted 13 September 2021; Published 22 September 2021

Academic Editor: Marcos Christian Bautista

Copyright (C) 2021 Zahra Ramezannia et al. This is an open access article distributed under the Creative Commons Attribution License, which permits unrestricted use, distribution, and reproduction in any medium, provided the original work is properly cited.

\begin{abstract}
Background. Acute respiratory tract infections (ARTIs) are the leading cause of illnesses in children. Human respiratory syncytial virus (HRSV) and human parainfluenza viruses (HPIVs) are among the most common etiologic agents associated with viral respiratory tract infections in children worldwide. Nevertheless, limited information is available on the spread of infections of these two viruses in northwest Iran. Objective. The purpose of the current study is to evaluate the frequency of RSV and HPIV-3 and clinical features among Iranian children with confirmed respiratory infections between April 2019 and March 2020. Methods. 100 nasopharyngeal swabs were collected from hospitalized patients (under 5 years old) with ARTI from Tabriz Children's Hospital. Detection of respiratory viruses was performed using the nested RT-PCR method. Results. Respiratory syncytial virus and HPIV-3 were recognized in 18\% (18/100) and 2\% (2/100) of children, respectively. Ten (55.6\%) of the RSV-positive samples were male, while 8 (44.4\%) were female. HPIV-3 was found only among 2 male patients (100\%). Most patients (61.1\%) with RSV infection were less than 12 months old. Additionally, samples that were positive for HPIV-3 were less than 12 months old. RSV infections had occurred mainly during the winter season. Conclusions. This study confirms that RSV can be one of the important respiratory pathogens in children in northwestern Iran. However, according to this study, HPIV-3 has a lower prevalence among children in this area than RSV. Therefore, implementing a routine diagnosis for respiratory pathogens can improve the management of respiratory infections in children.
\end{abstract}

\section{Introduction}

Acute respiratory tract infection (ARTI) is a common reason for hospitalization in children that continues to threaten public health. ARTI is the leading cause of morbidity and mortality among children under 5 in developing or low- and middle-income countries $[1,2]$. ARTI is commonly caused by viruses, including human respiratory syncytial virus (HRSV), human parainfluenza virus (HPIV), human bocavirus virus (HBoV), human coronavirus (HCoVs), influenza virus (IFV), and adenovirus (HAdV) [3-6]. Several bacteria also cause ARTI; however, studies show that most ARTIs are associated with viral infections [7]. RSV, which belongs to the family of Paramyxoviridae, is a common cause of acute respiratory tract infections in infants and toddlers that is a cause of bronchiolitis and pneumonia [8]. While RSV infection is usually described as a pediatric illness and a risk factor for asthma in childhood, the immunocompromised and elderly, especially those with previous pulmonary problems, also suffer from this virus [9]. In children under 5 
years, annually, RSV can be responsible for 34 million new lower respiratory tract infection (LRTI) episodes and 3.4 million hospital admissions worldwide [1]. Human parainfluenza viruses are another member of the Paramyxoviridae family, one of the leading causes of lower and upper respiratory tract infections in children under five years after RSV. HPIVs have been classified into four serotypes: HPIV-1, -2 , -3 , and -4 . Especially, HPIV-3 is associated with pneumonia and bronchiolitis in children under 1 year, and most children experience it in the first 2 years after birth [10-13]. Nevertheless, little information has been published on the disease burden and epidemiology of HPIV and RSV in the pediatric population of Iran, particularly in the northwest of Iran. This study aimed to determine the frequency of RSV and HPIV-3 in children less than 5 years of age with acute respiratory infection in the northwest of Iran. In addition, we evaluated the clinical manifestations among these hospitalized children in 2019-2020.

\section{Materials and Methods}

2.1. Patients and Specimens. This cross-sectional study has been conducted between April 2019 and March 2020. A total of 100 children from birth to 60 months who had shown ARTI symptoms were recruited at the time of hospitalization from Tabriz Children's Hospital. The demographic information, clinical manifestations, and medical records were included in a standardized questionnaire. In addition, nasopharyngeal and throat swabs were collected from each patient by a qualified medical personnel. Specimens were placed in $3 \mathrm{ml}$ of viral transport medium (VTM) and then was delivered to a virology laboratory via a cold chain and stored at $-80^{\circ} \mathrm{C}$ before analysis. Patients with immunosuppression and those with transplants or neoplasia were excluded. Using the nested RT-PCR technique, all specimens were tested for two respiratory viruses, including HPIV-3 and RSV.

2.2. Ethics Statement. This study was approved by the Ethics Committee of Tabriz University of Medical Sciences (ethical code: IR.TBZMED.REC.1398.112). Therefore, after obtaining informed written consent from parents, sampling was performed.

2.3. RNA Extraction and cDNA Synthesis. According to the manufacturer's instructions, viral RNA was extracted from all samples using the RNX-PLUS kit (Sinaclon, Iran). In brief, $1 \mathrm{ml}$ of RNX-PLUS solution and $200 \mu \mathrm{l}$ of chloroform were added to the tube containing the sample. Then, the mixture was centrifuged at $12000 \mathrm{~g}$ at $4^{\circ} \mathrm{C}$ for $15 \mathrm{~min}$. Next, the aqueous phase was transferred to a new tube, and an equal volume of isopropanol was added. The supernatant was discarded after centrifugation, and $1 \mathrm{ml}$ of $75 \%$ ethanol was added to the mixture. Afterward, the supernatant was removed, and the sediment was dried at room temperature. The concentration of the RNAs extracted was measured using a spectrophotometer. Following this, complementary DNA (cDNA) synthesis was performed using SinaClon first-strand cDNA synthesis kit according to manufacturer's instructions.
2.4. Virus Detection. Primers were synthesized by Pishgam Biotech. Seminested RT-PCR and heminested RT-PCR assays were performed to detect RSV and HPIV-3, respectively (Table 1). This was carried out using master mix PCR (Yektatajhiz, Iran). After cDNA synthesis, in the first PCR to detect RSV, $2 \mu \mathrm{l}$ DNA template was added to $23 \mu \mathrm{l}$ of reaction mixture containing $12.5 \mu \mathrm{l}$ master mix, $8.5 \mu \mathrm{l}$ distilled water, and $1 \mu \mathrm{l}$ of each primer (forward 1 and reverse 2) $(10 \mu \mathrm{M})$ (Table 1). Temperature and time profiles were as follows: 1 cycle at $94^{\circ} \mathrm{C}$ for $2 \mathrm{~min}$, followed by 40 cycles of $94^{\circ} \mathrm{C}$ for $45 \mathrm{~s}$, $59.9^{\circ} \mathrm{C}$ for $30 \mathrm{~s}, 72^{\circ} \mathrm{C}$ for $1 \mathrm{~min}$, and final extension at $72^{\circ} \mathrm{C}$ for $5 \mathrm{~min}$. Then, $2 \mu \mathrm{l}$ of the first PCR was added to a second PCR (PCR 2) in which the mixture contained $12.5 \mu \mathrm{l}$ of the master mix, $1 \mu \mathrm{l}$ of (forward 1) and $2 \mu \mathrm{l}$ of (reverse 3 ), and $7.5 \mu \mathrm{l}$ of distilled water in a final volume of $25 \mu \mathrm{l}$. Temperature and time profiles at this step were as follows: 1 cycle at $94^{\circ} \mathrm{C}$ for 2 min, followed by 40 cycles of denaturing, annealing, and extension $\left(45 \mathrm{~s}\right.$ at $94^{\circ} \mathrm{C}, 30 \mathrm{~s}$ at $54.5^{\circ} \mathrm{C}$, and $1 \mathrm{~min}$ at $72^{\circ} \mathrm{C}$ ), and final extension $5 \mathrm{~min}$ at $72^{\circ} \mathrm{C}$.

The steps and PCR reaction mixture for detection of HPIV3 were the same as RSV, but with specific HPIV-3 primers (Table 1). Temperature and time profiles were as follows: for the first PCR, 1 cycle at $94^{\circ} \mathrm{C}$ for $2 \mathrm{~min}$, followed by 40 cycles of $94^{\circ} \mathrm{C}$ for $45 \mathrm{~s}, 56.9^{\circ} \mathrm{C}$ for $30 \mathrm{~s}, 72^{\circ} \mathrm{C}$ for $1 \mathrm{~min}$, and final extension at $72^{\circ} \mathrm{C}$ for $5 \mathrm{~min}$; and in the second PCR, 1 cycle at $94^{\circ} \mathrm{C}$ for $2 \mathrm{~min}$, followed by 40 cycles of $94^{\circ} \mathrm{C}$ for $45 \mathrm{~s}, 52.6^{\circ} \mathrm{C}$ for $30 \mathrm{~s}$, $72^{\circ} \mathrm{C}$ for $1 \mathrm{~min}$, and final extension at $72^{\circ} \mathrm{C}$ for $5 \mathrm{~min}$. The negative (distilled water) and positive (RSV and HPIV-3 known samples) controls were placed in each run (Figure 1).

2.5. Statistical Analysis. Frequency and percentage were used to display qualitative data (sex, age groups, clinical manifestations of patients, and type of virus isolates). The Chi-square test was used to compare the qualitative data between types of virus isolates. The data were analyzed using SPSS software version 21. Statistical significance level was considered below 0.05 .

\section{Results}

3.1. Patient Characteristics. Of 100 enrolled children (under 5 years old), 44 were girls and 56 were boys. No significant difference was observed in gender. The age distribution of the study population was as follows: less than 12 months (53\%), 13-36 months (33\%), and 37-60 months (14\%). RSV and HPIV-3 tests were positive in $18(18 \%)$ and $2(2 \%)$ patients with acute respiratory tract infection, respectively. There was no statistically significant association between RSV infection and HPIV-3 infection with patients' age and gender $(P>0.05)$ (Table 2$)$.

3.2. Seasonal Distribution. Among the samples obtained from April 2019 to March 2020, cases of RSV were observed during the study period. From December, an increase of positive cases was observed, particularly in January and February, and a decrease during spring and summer $(P=0.002)$. Additionally, HPIV-3-positive samples were detected in the spring. 
TABLE 1: Sequences of oligonucleotides used for detection of RSV and HPIV-3.

\begin{tabular}{lccc}
\hline Primers name & $\begin{array}{c}\text { Target } \\
\text { gene }\end{array}$ & Sequence (5' to $\left.3^{\prime}\right)$ & Product size (bp) Reference \\
\hline Seminested RT-PCR for RSV & $\mathrm{N}$ & Forward (1): GGAACAAGTTGTTGAGGTTTATGA & ATATGC \\
& & $\begin{array}{c}\text { Reverse (2): TTCTGCTGTCAAGTCTAGTACACT GTAGT } \\
\text { Reverse (3): TTCTGCTGTCAAGTCTAGTACACTGTA GT }\end{array}$ & 180 \\
$\begin{array}{l}\text { Heminested RT-PCR for } \\
\text { HPIV-3 }\end{array}$ & HN & Forward (1): CTCGACGTTGTCAGGATATAG & 189 \\
\hline
\end{tabular}

Abbreviations. N: nucleocapsid; HN: hemagglutinin-neuraminidase.

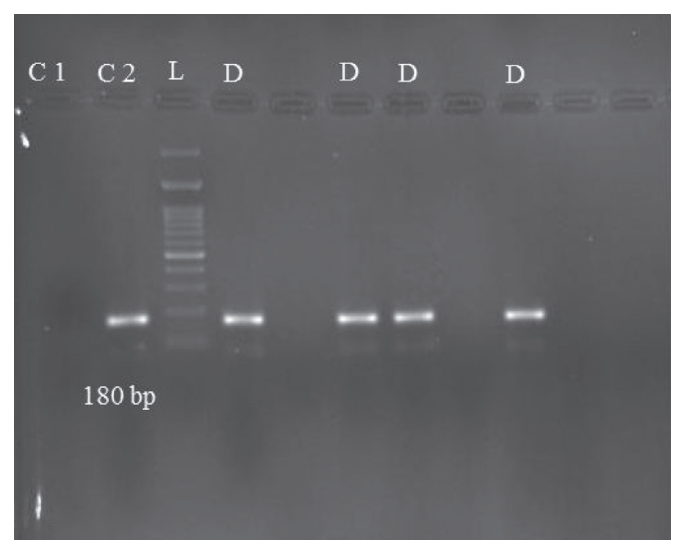

(a)

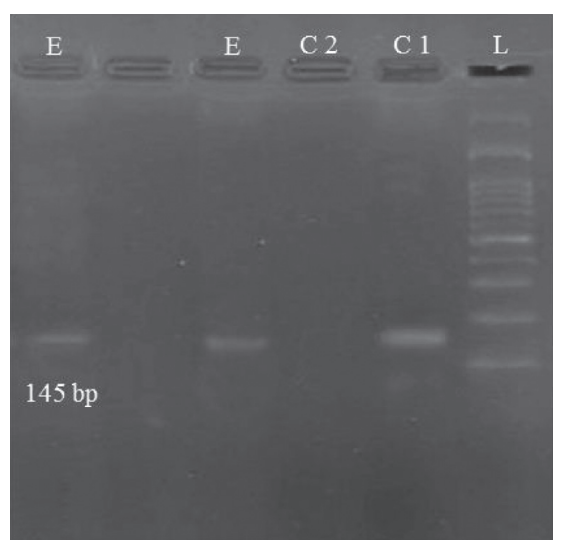

(b)

FIGURE 1: Agarose gel electrophoresis of the nested RT-PCR of RSV (a) and HPIV-3 (b). In (a), C1: negative control; C2: positive control; L: 100-bp DNA ladder; D: RSV-positive samples (180-bp). In (b), C1: positive control; C2: negative control; L: 100-bp ladder; E: HPIV-3positive samples (145-bp).

TABLE 2: Characteristics of the study population with ARTI disease $(n=100)$.

\begin{tabular}{|c|c|c|c|c|c|c|c|}
\hline \multirow{2}{*}{ Variable } & \multirow{2}{*}{ Total $(N=100)$} & \multicolumn{3}{|c|}{ RSV } & \multicolumn{3}{|c|}{ HPIV-3 } \\
\hline & & Positive $(N=18)$ & Negative $(N=82)$ & $P$ value & Positive $(N=2)$ & Negative $(N=98)$ & $P$ value \\
\hline Gender & & & & 0.967 & & & 0.205 \\
\hline Male & $56(56.0 \%)$ & $10(17.9 \%)$ & $46(82.1 \%)$ & & $2(3.6 \%)$ & $54(96.4 \%)$ & \\
\hline Female & $44(44.0 \%)$ & $8(18.2 \%)$ & $36(81.8 \%)$ & & $0(0.0 \%)$ & $44(100 \%)$ & \\
\hline Age groups (month) & & & & 0.746 & & & 0.405 \\
\hline$\leq 12$ & $53(53.0 \%)$ & $11(20.8 \%)$ & $42(79.2 \%)$ & & $2(3.8 \%)$ & $51(96.2 \%)$ & \\
\hline $13-36$ & $33(33.0 \%)$ & $5(15.2 \%)$ & $28(84.8 \%)$ & & $0(0.0 \%)$ & $33(100 \%)$ & \\
\hline $37-60$ & $14(14.0 \%)$ & $2(14.3 \%)$ & $12(85.7 \%)$ & & $0(0.0 \%)$ & $14(100 \%)$ & \\
\hline
\end{tabular}

Abbreviations. ARTI: acute respiratory tract infection; RSV: respiratory syncytial virus; HPIV-3: human parainfluenza virus 3 .

\subsection{Respiratory Pathogens and Clinical Characteristics.} Clinical features for these two viral infections were examined. Symptoms recorded in patients included fever, wheezing, cough, vomiting, diarrhea, pneumonia, runny nose, cyanosis, tachypnea, and dyspnea. Common symptoms in children with RSV infection included wheezing (66.7\%), cough $(61.1 \%)$, fever $(55.6 \%)$, vomiting and pneumonia $(33.3 \%)$, and runny nose $(27.8 \%)$. In addition, children recognized with RSV had a higher proportion of tachypnea $(P=0.005)$ than children that were not. Furthermore, tachypnea was predominant in boys with RSV infection $(P=0.043)$ (Table 3$)$.

\section{Discussion}

This study indicated that RSV and HPIV-3 are among the important respiratory pathogens associated with acute respiratory infections in young children in northwest Iran. In the present study, the frequency of RSV and HPIV-3 in children under 5 years of age was $18 \%$ and $2 \%$, respectively. Overall, there is limited evidence on the epidemiological burden of RSV and HPIV-3 in the northwest of Iran in the published literature. According to the results of a metaanalysis from 1996 to 2013, the prevalence of RSV infection in Iran was reported to be $18.7 \%$ [15]. One of the studies that 
TABLE 3: Association of symptoms with respiratory syncytial virus infection and parainfluenza 3.

\begin{tabular}{|c|c|c|c|c|c|c|}
\hline \multirow{2}{*}{ Clinical manifestations of patients } & \multicolumn{3}{|c|}{ RSV } & \multicolumn{3}{|c|}{ HPIV } \\
\hline & Positive & Negative & $P$ value & Positive & Negative & $P$ value \\
\hline Wheezing & & & 0.003 & & & 0.28 \\
\hline Yes & $12(33.3 \%)$ & $24(66.7 \%)$ & & $0(0 \%)$ & $36(100 \%)$ & \\
\hline No & $6(9.4 \%)$ & $58(90.6 \%)$ & & $2(3.1 \%)$ & $62(96.9 \%)$ & \\
\hline Fever & & & 0.17 & & & 0.33 \\
\hline Yes & $10(14.5 \%)$ & $59(85.5 \%)$ & & $2(2.9 \%)$ & $67(97.1 \%)$ & \\
\hline No & $8(25.5 \%)$ & $23(74.2 \%)$ & & $0(0.0 \%)$ & $31(100 \%)$ & \\
\hline Vomiting & & & 0.46 & & & 0.79 \\
\hline Yes & $6(14.6 \%)$ & $35(85.4 \%)$ & & $1(2.4 \%)$ & $40(97.6 \%)$ & \\
\hline No & $12(20.3 \%)$ & $47(97.7 \%)$ & & $1(1.7 \%)$ & $58(98.3 \%)$ & \\
\hline Diarrhea & & & 0.12 & & & 0.23 \\
\hline Yes & $1(5.6 \%)$ & $17(94.4 \%)$ & & $1(5.6 \%)$ & $17(94.4 \%)$ & \\
\hline No & $17(20.7 \%)$ & $65(79.3 \%)$ & & $1(1.2 \%)$ & $81(98.8 \%)$ & \\
\hline Pneumonia & & & 0.08 & & & 0.25 \\
\hline Yes & $6(31.6 \%)$ & $13(68.4 \%)$ & & $1(5.3 \%)$ & $18(94.7 \%)$ & \\
\hline No & $12(14.8 \%)$ & $69(85.2 \%)$ & & $1(1.2 \%)$ & $80(98.8 \%)$ & \\
\hline Cough & & & 0.21 & & & 0.39 \\
\hline Yes & $11(15.1 \%)$ & $62(84.9 \%)$ & & $2(2.7 \%)$ & $72(97.3 \%)$ & \\
\hline No & $7(25.9 \%)$ & $20(74.1 \%)$ & & $0(0 \%)$ & $26(100 \%)$ & \\
\hline Runny nose & & & 0.10 & & & 0.88 \\
\hline Yes & $5(11.1 \%)$ & $40(88.9 \%)$ & & $1(2.2 \%)$ & $44(97.8 \%)$ & \\
\hline No & $13(23.6 \%)$ & $42(76.4 \%)$ & & $1(1.8 \%)$ & $54(98.2 \%)$ & \\
\hline Cyanosis & & & 0.63 & & & 0.83 \\
\hline Yes & $0(0 \%)$ & $1(100 \%)$ & & $0(0 \%)$ & $2(100 \%)$ & \\
\hline No & $18(18.2 \%)$ & $81(81.8 \%)$ & & $2(2 \%)$ & $96(98 \%)$ & \\
\hline Tachypnea & & & 0.005 & & & 0.69 \\
\hline Yes & $4(57.1 \%)$ & $3(42.9 \%)$ & & $0(0 \%)$ & $7(100 \%)$ & \\
\hline No & $14(15.1 \%)$ & $79(84.9 \%)$ & & $2(2.2 \%)$ & $91(97.8 \%)$ & \\
\hline Shortness of breath & & & 0.85 & & & 0.016 \\
\hline Yes & $5(19.2 \%)$ & $21(80.8 \%)$ & & $2(7.7 \%)$ & $24(92.3 \%)$ & \\
\hline No & $14(17.6 \%)$ & $61(82.4 \%)$ & & $0(0 \%)$ & $74(100 \%)$ & \\
\hline
\end{tabular}

Abbreviations. RSV: respiratory syncytial virus; HPIV-3: human parainfluenza virus 3.

investigated the prevalence of RSV in northwestern Iran was conducted by Jedari et al. in 2002; they evaluated RSV infection in children under 5 years of age with lower respiratory tract infection by immunofluorescence assay and reported that RSV was the cause of $24.6 \%$ of the cases [16]. Pourakbari et al., in 2014, found that, among 232 children with acute respiratory infections, $17.2 \%$ were RSV positive in Tehran, Iran [17]. In another study from Tehran, the prevalence of RSV among children between 2008 and 2009 was $16.8 \%$ [14]. According to the mentioned results above, the results of our study are similar to the prevalence of RSV in other studies led in Iran. However, additional studies have been conducted in southern Iran, which shows a higher percentage of the prevalence of RSV than our study. For instance, one study found that $30 \%$ of children with ARI were positive for RSV in Shiraz in 2015 [18]. Furthermore, according to a systematic review study from 2001 to 2019 in the Middle-East and North Africa, the prevalence of RSV is generally $24.4 \%$, higher than our study's results [19]. Similarly, a study from India conducted between August 2011 till 2013 reported a $24.5 \%$ prevalence of RSV among children under 5 years of age [20]. In this study, RSV was mostly found in male infants. Likewise, most positive cases were less than one year old, similar to other studies $[14,21]$. There was no difference in clinical symptoms such as wheezing, fever, cough, vomiting, diarrhea, pneumonia, runny nose, and cyanosis in RSV-positive patients compared to RSV-negative patients and only a significant difference between the two groups in tachypnea. However, tachypnea was more common in RSV-positive patients. Like our study, Lu et al. in China reported that tachypnea was more frequent in RSVpositive infants than in RSV-negative infants [22]. Meanwhile, wheezing, cough, and fever were the common clinical signs and symptoms in these children. Moattari et al. reported that cough, wheezing, and bronchiolitis were more common in RSV-positive patients; however, similar to our study, they found no difference in other clinical symptoms between the two groups [18]. Since there are no other studies reported on the prevalence of parainfluenza virus 3 or other types in the northwest of Iran, our study results gain significance. The human parainfluenza virus 3 , like most RSVpositive samples, was found in infants less than 12 months of age, and also, HPIV-3-positive samples were found in the spring. The prevalence of HPIV-3 in our study was almost close to other parts of Iran, such as Tehran. In a study conducted in 2010, the HPIV-3 rate of $4.4 \%$, and in another study in 2014, a prevalence of $8.4 \%$ for HPIV-1-4 were reported by Shatizadeh et al. [14, 23]. Al-Ayed et al. found a $1.8 \%$ HPIV-3 frequency in children under 5 years with ARTI diagnosis between October 2012 and July 2013 in Saudi 
Arabia [24]. Variously, in other Asian countries such as Bangladesh, the prevalence of HPIV-3 was reported to be 10.5\% among children between August 2014 and July 2015 [25]. In addition, a recent study reported that the prevalence of HPIV in children under 5 years of age in most Middle-East countries was more than $15 \%$, but did not specifically report the prevalence of HPIV-3 [26]. In the present study, the RSV seasonal distribution is defined by the fall and winter peaks. Our study shows a lower prevalence of RSV in spring, which, according to previous studies in Iran, have been diagnosed with RSV infection during the cold season from November to March [15]. In other parts of the world, the seasonal distribution of RSV can vary depending on geographical location, high precipitation rate, and cold temperature. But in general, strong seasonal distribution with high prevalence during the winter is observed in most places [19]. Further epidemiological studies are needed to evaluate the seasonal patterns of RSV and HPIV infections in Iran. There are some limitations in this study, including the relatively small sample size and the lack of some clinical information that can be mentioned. Also, recognizing other viral pathogens, other HPIV types, and RSV strain identification and virus genotyping has not been investigated in this study. Several studies have reported a high rate of RSV coinfection with other respiratory viruses and bacterial pathogens. Hence, in analyzing the burden of illness associated with RSV infection, coinfections are a major confounder that cannot be ignored [27]. Some factors allow us to attain a more accurate assessment of the true burden of RSV and other respiratory viruses in the northwest of Iran, such as further studies on outpatients with acute respiratory infections, annual monitoring of the prevalence of respiratory viruses, and considering children with special conditions such as premature infants. This information will be important for understanding viral epidemics.

\section{Conclusion}

According to our findings, RSV can be one of the important respiratory pathogens in children in northwestern Iran. Also, HPIV-3 had a low prevalence among children in this area than RSV. Consequently, implementing a routine diagnosis for respiratory pathogens can improve the management of respiratory infections in children and help combat ARTI.

\section{Data Availability}

The data used to support the findings of this study are included within the article.

\section{Disclosure}

This study was extracted from a master's thesis written by Zahra Ramezannia.

\section{Conflicts of Interest}

The authors declare they have no conflicts of interest.

\section{Acknowledgments}

The authors thank all the faculty members of the Department of Microbiology and Virology and the medical staff of Tabriz Children's Hospital. The authors also thank Dr. Afagh Moattari and Dr. Vahid Salimi for providing positive control for this study. This study was financially supported by the Tabriz University of Medical Sciences (grant no. 62143).

\section{References}

[1] H. Nair, D. J. Nokes, B. D. Gessner et al., "Global burden of acute lower respiratory infections due to respiratory syncytial virus in young children: a systematic review and metaanalysis," The Lancet, vol. 375, no. 9725, pp. 1545-1555, 2010.

[2] H. Wang, Y. Zheng, J. Deng et al., "Prevalence of respiratory viruses among children hospitalized from respiratory infections in Shenzhen, China," Virology Journal, vol. 13, no. 1, p. 39, 2016.

[3] R. Brittain-Long, S. Nord, S. Olofsson, J. Westin, L.-M. Anderson, and M. Lindh, "Multiplex real-time PCR for detection of respiratory tract infections," Journal of Clinical Virology, vol. 41, no. 1, pp. 53-56, 2008.

[4] J. S. Tregoning and J. Schwarze, "Respiratory viral infections in infants: causes, clinical symptoms, virology, and immunology," Clinical Microbiology Reviews, vol. 23, no. 1, pp. 74-98, 2010.

[5] J.-r. Song, Y. Jin, Z.-p. Xie et al., "Novel human bocavirus in children with acute respiratory tract infection," Emerging Infectious Diseases, vol. 16, no. 2, pp. 324-327, 2010.

[6] Y. Jin, R.-f. Zhang, Z.-p. Xie et al., "Prevalence of adenovirus in children with acute respiratory tract infection in Lanzhou, China," Virology Journal, vol. 10, no. 1, p. 271, 2013.

[7] K. McIntosh, "Community-acquired pneumonia in children," New England Journal of Medicine, vol. 346, no. 6, pp. 429-437, 2002.

[8] D. K. Shay, R. C. Holman, R. D. Newman, L. L. Liu, J. W. Stout, and L. J. Anderson, "Bronchiolitis-associated hospitalizations among US children, 1980-1996," JAMA, vol. 282, no. 15, pp. 1440-1446, 1999.

[9] W. W. Thompson, D. K. Shay, E. Weintraub et al., "Mortality associated with influenza and respiratory syncytial virus in the United States," JAMA, vol. 289, no. 2, pp. 179-186, 2003.

[10] H. Hasman, C. T. Pachucki, A. Unal et al., "Aetiology of influenza-like illness in adults includes parainfluenzavirus type 4," Journal of Medical Microbiology, vol. 58, no. 4, pp. 408-413, 2009.

[11] K. J. Henrickson, "Parainfluenza viruses," Clinical Microbiology Reviews, vol. 16, no. 2, pp. 242-264, 2003.

[12] C. B. Hall, "Respiratory syncytial virus and parainfluenza virus," New England Journal of Medicine, vol. 344, no. 25, pp. 1917-1928, 2001.

[13] H.-T. Yang, Q. Jiang, X. Zhou et al., "Identification of a natural human serotype 3 parainfluenza virus," Virology Journal, vol. 8, no. 1, p. 58, 2011.

[14] S. Shatizadeh, J. Yavarian, F. Rezaie, M. Mahmoodi, M. Naseri, and T. Mokhtari Azad, "Epidemiological and clinical evaluation of children with respiratory virus infections," Medical Journal of the Islamic Republic of Iran, vol. 28, p. 102, 2014.

[15] V. Salimi, M. Tavakoli-Yaraki, J. Yavarian, L. Bont, and T. Mokhtari-Azad, "Prevalence of human respiratory syncytial virus circulating in Iran," Journal of Infection and Public Health, vol. 9, no. 2, pp. 125-135, 2016. 
[16] S. S. Jedari, N. M. Rahbani, A. Jalali, A. Aghazadeh, and S. Ebrahimpour, "A study of lower respiratory tract infection by respiratory syncytial virus in infants and young children," Medical Journal of Tabriz University of Medical Sciences, vol. 55, p. 11, 2002.

[17] B. Pourakbari, S. Mahmoudi, Z. Movahedi et al., "Viral etiology of acute lower respiratory tract infections in hospitalized young children in a children's referral hospital in Iran," Turkish Journal of Pediatrics, vol. 56, no. 4, pp. 354-9, 2014.

[18] A. Moattari, S. Aleyasin, A. Emami, M. Fyruzi, and N. Pirbonyeh, "The prevalence of human metapneumovirus and respiratory syncytial virus and coinfection with both in hospitalized children with acute respiratory infection in South of Iran," Archives of Pediatric Infectious Diseases, vol. 3, no. 3, 2015.

[19] H. M. Yassine, M. U. Sohail, N. Younes, and G. K. Nasrallah, "Systematic review of the respiratory syncytial virus (RSV) prevalence, genotype distribution, and seasonality in children from the Middle East and North Africa (MENA) region," Microorganisms, vol. 8, no. 5, p. 713, 2020.

[20] S. Kini, B. S. Kalal, S. Chandy, R. Shamsundar, and A. Shet, "Prevalence of respiratory syncytial virus infection among children hospitalized with acute lower respiratory tract infections in Southern India," World Journal of Clinical Pediatrics, vol. 8, no. 2, pp. 33-42, 2019.

[21] M. Parsania, B. Poopak, M. H. Pouriayevali, S. Haghighi, A. Amirkhani, and A. Nateghian, "Detection of human metapneumovirus and respiratory syncytial virus by real-time polymerase chain reaction among hospitalized young children in Iran," Jundishapur Journal of Microbiology, vol. 9, no. 3, Article ID e32974, 2016.

[22] L. Lu, Y. Yan, B. Yang et al., "Epidemiological and clinical profiles of respiratory syncytial virus infection in hospitalized neonates in Suzhou, China," BMC Infectious Diseases, vol. 15, no. 1, p. 431, 2015.

[23] S. Shatizadeh Malekshahi, T. Mokhtari Azad, J. Yavarian, S. Shahmahmoodi, M. Naseri, and F. Rezaei, "Molecular detection of respiratory viruses in clinical specimens from children with acute respiratory disease in Iran," Pediatric Infectious Disease Journal, vol. 29, no. 10, pp. 931-933, 2010.

[24] M. S. Al-Ayed, A. M. Asaad, M. A. Qureshi, and M. S. Ameen, "Viral etiology of respiratory infections in children in southwestern Saudi Arabia using multiplex reverse-transcriptase polymerase chain reaction," Saudi Medical Journal, vol. 35, no. 11, p. 1348, 2014.

[25] G. S. Bhuyan, M. A. Hossain, S. K. Sarker et al., "Bacterial and viral pathogen spectra of acute respiratory infections in under-5 children in hospital settings in Dhaka city," PLoS One, vol. 12, no. 3, Article ID e0174488, 2017.

[26] R. A. Rafeek, M. V. Divarathna, and F. Noordeen, “A review on disease burden and epidemiology of childhood parainfluenza virus infections in Asian countries," Reviews in Medical Virology, vol. 31, Article ID e2164, 2020.

[27] L. Bont, P. A. Checchia, B. Fauroux et al., "Defining the epidemiology and burden of severe respiratory syncytial virus infection among infants and children in western countries," Infectious Diseases and Therapy, vol. 5, no. 3, pp. 271-298, 2016. 